\title{
Long Term Survival in Patients with Metastatic Adenocarcinoma of the Lung in the Era of Targeted Agents
}

Doru Paul ${ }^{1}$ and Marissa Rybstein ${ }^{2}$

1 Division of Hematology-Oncology, Department of Medicine, Weill Cornell Medicine/New York Presbyterian Hospital, New York, New York

${ }^{2}$ Division of Hematology-Oncology, Department of Medicine, NYU Long Island School of Medicine

Corresponding Author: Doru Paul; e-mail: dop9054@med.cornell.edu

\section{Abstract}

Introduction: Several studies have shown that tyrosine kinase inhibitors (TKI) and chemotherapy improve the short term and median survival of patients with metastatic adenocarcinoma of the lung (MAL), but there is less data on the long-term survival (LTS) of these patients.

Methods: A univariate retrospective analysis was performed on 174 patients with MAL diagnosed at our institution between 2009 and 2011, and with up to a 5-year follow-up. Overall survival was estimated using the product-limit method and drawing the KaplanMeier curves and compared using the log-rank test.

Results: Factors associated with a statistically significant survival benefit in our patients were having undergone lung surgery, female gender, never smokers, bronchioalveolar histology, and lower TNM nodal stage. Particularly, prior lung surgery was shown to improve survival in patients treated with erlotinib. This was also true when comparing patients from a historical cohort as well. Among patients with Epidermal Growth Factor Receptor (EGFR) mutation, there was no statistically significant difference in survival amongst patients treated with either surgery or erlotinib.

Conclusion: In our patients with MAL the only treatment modality that improved LTS in a statistically significant way was lung surgery. This is an important finding as National Cancer Comprehensive Network (NCCN) guidelines consider surgery as a treatment option only in MAL with isolated lesions.

Keywords: lung cancer, targeted therapy, EGFR mutation, long term survival 


\section{Introduction}

According to the Surveillance, Epidemiology and End Results (SEER) database, lung cancer remains the leading cause of cancer related deaths in the United States. The number of projected new lung cancer cases for 2021 is 235,760 , which compromised $12.4 \%$ of all new cancer cases (1). Given the significant healthcare burden that this group of malignancies poses, improving long-term outcomes for these patients is extremely important.

Over the past years, the treatment landscape for lung cancer has changed dramatically, with the approval of several checkpoint inhibitors for use in various histologic subtypes and lines of therapy. Despite this advance, patients with non-small cell carcinoma (NSCLC) harboring driver mutations were excluded from immunotherapy studies, and their treatment options have been focused on the use of targeted therapies.

The use of next generation sequencing (NGS) methods allowed for the discovery and description of mutations that are considered fundamental for cancer transformation and progression. Targetable driver mutations are present in all histological types of NSCLC (including adenocarcinoma, squamous cell carcinoma (SCC), and large cell carcinoma), but they are most commonly found in adenocarcinoma. In-depth characterization of these mutations fully benefited the treatment of cancer, and FDA clinically approved several small molecules targeting key protein products of these aberrant genes. In lung adenocarcinoma, the most common "driver" mutation occurs within epidermal growth factor receptor (EGFR) gene. EGFR is a transmembrane tyrosine kinase receptor that has been shown to be overexpressed, leading to worse overall survival in many malignancies, particularly NSCLC (2). Several mutations in the EGFR gene have been found to lead to this overexpression or constitutive activity of the receptor and promote oncogenesis (3). Erlo- tinib (Tarceva, OSI Oncology/ Genentech/ Roche), a tyrosine kinase inhibitor was approved for metastatic lung adenocarcinoma in the recurrent setting in 2004 (4). In 2010, in advanced NSCLC, it was approved as maintenance therapy after platinum chemotherapy, and in 2013 it was approved as first-line single agent in patients with advanced NSCLC with an EGFR mutation $(5,6)$.

Several studies showed a benefit in progression free survival (PFS) in patients with advanced EGFR mutated lung adenocarcinoma (Stage IIIB/IV) who received either treatment with erlotinib, or chemotherapy (7). None of these studies showed a benefit in the overall survival of patients that received erlotinib, thus the long-term survival of such patients has remained ill defined. In 2016, Lin et al. published data for 5 year survival of 137 patients with EGFR mutated MAL treated with erlotinib with a $14.6 \% 5$ year survival rate. Factors that were found to be associated with longer overall survival were exon 19 deletion, absence of extrathoracic (in general), or, specifically, brain metastases, and non-smoking status (8). Initially we analyzed data for patients treated during 2003-2008.

The aim of this study is to address the issue of overall survival in patients treated with erlotinib and to identify factors that may influence it.

\section{Materials and methods}

\section{Patients}

We reviewed the North Shore Hospital tumor registry and Monter Cancer Center medical records between 2009 and 2011 and identified 174 patients diagnosed with metastatic adenocarcinoma of the lung (MAL).

We chose the 2009-2011 interval for several reasons: in 2009 the IPASS randomized trial proved the benefit of TKIs in the treatment of patients with EGFR-mu- 
tated MAL (9); also in 2009 erlotinib started to be used in the frontline setting of EGFR mutated metastatic adenocarcinoma of the lung in USA, with only two other TKIs, afatinib and gefitinib, approved in the same setting. We analyzed only patients treated with erlotinib.

A cohort of patients diagnosed with MAL during 2003-2008 was also used for comparison. 298 patients were initially identified, 79 patients were removed because of incomplete data and 219 patients were considered for analysis.

We collected the following information: age, sex, date of diagnosis, vital status, survival and treatment i.e. erlotinib, chemotherapy, surgery including type of surgery, radiotherapy including duration and organ targeted by radiotherapy, EGFR mutational status and type of mutations (when known), site of metastases: lung only, bone only, brain metastases (mets), nodal status, presence or not of bronchioalveolar histology.

\section{Exclusions}

Patients were excluded from the analysis if they did not receive any treatments i.e. chemotherapy, surgery, radiotherapy or erlotinib, or if their chemotherapy or radiotherapy treatment status was unknown. There were no patients with unknown status for surgery. 59 patients were excluded based on these criteria.

\section{Statistical analysis}

We collected descriptive statistics data for demographic factors including age at diagnosis, gender, smoking status (never, former, current), location of metastases (lung/brain/bone), EGFR mutation status, treatment regimen (chemotherapy, erlotinib, radiotherapy, surgery), radiotherapy target (brain, lung, palliative), type of surgery (lobectomy, wedge resection), bronchioalveolar histology, nodal status, survival in months, survival status (dead/alive). We used descriptive statistical methods for analysis (mean and standard deviation for continuous factors, proportion for continuous factors).

All the computations were done using a statistical analysis software (SAS). For each demographic factor given above, overall survival was estimated using the product-limit method and compared using the log-rank test. Those factors that were significantly associated with overall survival in this univariable screen $(p<0.05)$ were described.

A univariate retrospective analysis was performed on 174 patients with MAL diagnosed at our institution between 2009 and 2011, and with up to a 5-year follow-up. Most patients received multiple treatment modalities. Overall survival was estimated using the product-limit method and drawing the Kaplan-Meier curves and compared using the log-rank test. Patients alive at last follow-up were censored.

Due to a limited number of patients, a multivariable Cox regression to examine the joint effects of different factors on overall survival was not performed. Backward selection was used to remove those variables that did not contribute information to the model.

\section{Results}

\section{Demographics}

Out of 174 patients analyzed, 33 patients received erlotinib, of which 13 had proven EGFR-mutated tumors. There were four statistically significant differences between the erlotinib group $(\mathrm{N}=33)$ and the nonerlotinib group ( $\mathrm{N}=141)$. First, the patients in the erlotinib group were older, with a mean age of 72.4 years vs 65.5 years in the nonerlotinib group $(p=0.0327)$. The second statistically significant difference between the two groups was the smoking status. The erlotinib group contained more never smokers than the non-erlotinib group $75 \%$ vs 
$13.5 \%(p<0.0001)$. The third statistically significant difference between the two groups was the administration of chemotherapy. $100 \%(33 / 33)$ of the patients in the erlotinib group received chemotherapy besides erlotinib. Only $80.9 \%(114 / 141)$ patients in the non-erlotinib group received chemotherapy $(p=0.0062)$. The fourth statistically significant difference was lung surgery. Only $3 \%$ $(1 / 33)$ of the patients in the erlotinib group had surgery vs $22.6 \%(26 / 141)$ of the patients in the non-erlotinib group.

Other factors like gender, bronchioalveolar component, nodal stage, the administration of radiotherapy, presence of lung, brain or bone only metastases were not statistically different between the two groups. The demographic data of the patients are included in Table 1.

Table 1. Demographic and Patients Clinical Characteristics

\begin{tabular}{|c|c|c|c|}
\hline & $\begin{array}{l}\text { Erlotinib } \\
\mathrm{n}=33\end{array}$ & $\begin{array}{l}\text { Non-Erlotinib } \\
\mathrm{n}=141\end{array}$ & \\
\hline Continuous Factors & $\begin{array}{l}\text { Mean (SD) } \\
\text { Median (Q1, Q3) }\end{array}$ & $\begin{array}{l}\text { Mean (SD) } \\
\text { Median (Q1, Q3) }\end{array}$ & p-value* \\
\hline Age & $\begin{array}{l}72.4(13.9) \\
74.0(61.0,82.0)\end{array}$ & $\begin{array}{l}66.5(11.4) \\
67.0(57.0,77.0)\end{array}$ & 0.0327 \\
\hline Categorical Factors & n (percent) & n (percent) & p-value ${ }^{\star *}$ \\
\hline \multicolumn{4}{|l|}{ Gender } \\
\hline Female & $21(63.6 \%)$ & $78(55.3 \%)$ & 0.3851 \\
\hline Male & $12(36.4 \%)$ & $63(44.7 \%)$ & \\
\hline \multicolumn{4}{|l|}{ Smoking Status ${ }^{* * *}$} \\
\hline Never & $24(75.0 \%)$ & $19(13.5 \%)$ & $<0.0001$ \\
\hline Former & $7(21.9 \%)$ & $76(53.9 \%)$ & \\
\hline Current & $1(3.1 \%)$ & $46(32.6 \%)$ & \\
\hline \multicolumn{4}{|c|}{ Bronchioalveolar Component $^{\star \star *}$} \\
\hline Yes & $1(3.0 \%)$ & $8(6.1 \%)$ & 0.6890 \\
\hline No & $32(97.0 \%)$ & $124(93.9 \%)$ & \\
\hline \multicolumn{4}{|l|}{ Nodal Stage $\mathrm{e}^{\star \star \star}$} \\
\hline 0 & $10(32.3 \%)$ & $36(27.5 \%)$ & 0.5958 \\
\hline $1-3$ & $21(67.7 \%)$ & $95(72.5 \%)$ & \\
\hline \multicolumn{4}{|l|}{ Lung Surgery } \\
\hline Yes & $1(3.0 \%)$ & $26(18.4 \%)$ & 0.0277 \\
\hline No & $32(97.0 \%)$ & $115(81.6 \%)$ & \\
\hline \multicolumn{4}{|l|}{ Chemotherapy } \\
\hline Yes & $33(100.0 \%)$ & $114(80.9 \%)$ & 0.0062 \\
\hline No & $0(0.0 \%)$ & $27(19.1 \%)$ & \\
\hline \multicolumn{4}{|l|}{ RT } \\
\hline Brain & $8(24.2 \%)$ & $38(27.0 \%)$ & 0.2512 \\
\hline Lung & $1(3.0 \%)$ & $17(12.1 \%)$ & \\
\hline Other or None & $24(72.7 \%)$ & $86(61.0 \%)$ & \\
\hline \multicolumn{4}{|c|}{ Lung Metastases Only ${ }^{* * *}$} \\
\hline Yes & $5(15.2 \%)$ & $26(19.0 \%)$ & 0.6093 \\
\hline No & $28(84.8 \%)$ & $111(81.0 \%)$ & \\
\hline \multicolumn{4}{|c|}{ Presence of Brain Metastases ${ }^{\star \star *}$} \\
\hline Yes & $11(33.3 \%)$ & $49(35.8 \%)$ & 0.7929 \\
\hline
\end{tabular}




\begin{tabular}{|l|l|l|l|}
\hline No & $22(66.7 \%)$ & $88(64.2 \%)$ & \\
\hline Bone Metastases Only*** & & & \\
\hline Yes & $5(15.2 \%)$ & $22(16.1 \%)$ & 0.8982 \\
\hline No & $28(84.8 \%)$ & $115(83.9 \%)$ & \\
\hline
\end{tabular}

* Mann-Whitney test

${ }^{* *}$ Chi-square test or Fisher's exact test, as appropriate

${ }^{* * *}$ sample sizes vary due to missing data

Table 2. Factors Associated with Survival in Patients with Metastatic Adenocarcinoma of the Lung

\begin{tabular}{|c|c|c|c|c|}
\hline \multirow[b]{2}{*}{ Factor } & \multicolumn{2}{|c|}{$\begin{array}{l}\text { Survival (\% alive) and Associated } \\
95 \% \text { Confidence Interval at: }\end{array}$} & \multirow[b]{2}{*}{$\begin{array}{l}\text { Median Survival in } \\
\text { Months }(95 \% \mathrm{Cl})\end{array}$} & \multirow[b]{2}{*}{ p-value } \\
\hline & 24 months & 60 months & & \\
\hline \multicolumn{5}{|l|}{ Treatment } \\
\hline Erlotinib & $\begin{array}{l}42.4 \% \\
(25.6 \%, 58.3 \%)\end{array}$ & $0.0 \%$ & $18.8(12.9,37.0)$ & \multirow[t]{2}{*}{0.0160} \\
\hline Non Erlotinib & $\begin{array}{l}18.8 \% \\
(12.7 \%, 25.8 \%)\end{array}$ & $\begin{array}{l}9.4 \% \\
(4.5 \%, 16.5 \%)\end{array}$ & $8.8(7.6,10.1)$ & \\
\hline \multicolumn{5}{|l|}{ Gender } \\
\hline Male & $\begin{array}{l}15.2 \% \\
(8.1 \%, 24.3 \%)\end{array}$ & $0.0 \%$ & $7.6(5.9,9.7)$ & \multirow[t]{2}{*}{0.0019} \\
\hline Female & $\begin{array}{l}29.4 \% \\
(20.7 \%, 38.7 \%)\end{array}$ & $\begin{array}{l}11.5 \% \\
(4.8 \%, 21.4 \%)\end{array}$ & $14.0(9.3,18.8)$ & \\
\hline \multicolumn{5}{|l|}{ Smoking Status } \\
\hline Never Smoker & $\begin{array}{l}40.1 \% \\
(25.2 \%, 54.5 \%)\end{array}$ & $\begin{array}{l}5.8 \% \\
(0.6 \%, 20.8 \%)\end{array}$ & $20.5(12.9,25.0)$ & \multirow[t]{3}{*}{0.0463} \\
\hline Current Smoker & $\begin{array}{l}17.5 \% \\
(8.2 \%, 29.6 \%)\end{array}$ & $0.0 \%$ & $8.7(4.8,14.9)$ & \\
\hline Former Smoker & $\begin{array}{l}17.1 \% \\
(10.0 \%, 26.0 \%)\end{array}$ & $\begin{array}{l}12.5 \% \\
(6.2 \%, 21.1 \%)\end{array}$ & $9.0(7.0,10.8)$ & \\
\hline \multicolumn{5}{|l|}{ Lung Surgery } \\
\hline Yes & $\begin{array}{l}51.9 \% \\
(31.9 \%, 68.5 \%)\end{array}$ & $\begin{array}{l}32.6 \% \\
(14.0 \%, 52.8 \%)\end{array}$ & $28.5\left(8.7,{ }^{*}\right)$ & \multirow[t]{2}{*}{$<0.0001$} \\
\hline No & $\begin{array}{l}17.9 \% \\
(12.1 \%, 24.7 \%)\end{array}$ & $0.0 \%$ & $9.3(8.1,11.9)$ & \\
\hline \multicolumn{5}{|l|}{ Radiotherapy } \\
\hline Brain & $\begin{array}{l}22.6 \% \\
(11.7 \%, 35.6 \%)\end{array}$ & $0.0 \%$ & $9.5(6.6,14.9)$ & \multirow[t]{3}{*}{0.0320} \\
\hline Lung & $\begin{array}{l}5.6 \% \\
(0.4 \%, 22.4 \%)\end{array}$ & $0.0 \%$ & $5.1(4.2,9.8)$ & \\
\hline Other or None & $\begin{array}{l}26.6 \% \\
(18.7 \%, 35.3 \%)\end{array}$ & $\begin{array}{l}11.0 \% \\
(4.9 \%, 19.9 \%)\end{array}$ & $12.5(8.7,15.3)$ & \\
\hline \multicolumn{5}{|l|}{ Chemotherapy } \\
\hline Yes & $\begin{array}{l}22.0 \% \\
(15.6 \%, 29.0 \%)\end{array}$ & $0.0 \%$ & $10.1(8.7,14.0)$ & \multirow[t]{2}{*}{0.7395} \\
\hline No & $\begin{array}{l}31.3 \% \\
(14.9 \%, 49.1 \%)\end{array}$ & $\begin{array}{l}19.6 \% \\
7.1 \%, 36.4 \%)\end{array}$ & $5.6(2.7,20.4)$ & \\
\hline Lung Mets Only & & & & \\
\hline
\end{tabular}




\begin{tabular}{|c|c|c|c|c|}
\hline Yes & $\begin{array}{l}44.6 \% \\
(26.7 \%, 61.0 \%)\end{array}$ & $\begin{array}{l}29.1 \% \\
(13.7 \%, 46.4 \%)\end{array}$ & $20.4(8.3,43.2)$ & \multirow[t]{2}{*}{0.0054} \\
\hline No & $\begin{array}{l}19.1 \% \\
(13.0 \%, 26.1 \%)\end{array}$ & $\begin{array}{l}4.0 \% \\
(0.9 \%, 10.7 \%)\end{array}$ & $9.5(8.1,12.7)$ & \\
\hline \multicolumn{5}{|c|}{$\begin{array}{l}\text { Brain Metastases } \\
\text { Present }\end{array}$} \\
\hline Yes & $\begin{array}{l}27.4 \% \\
(16.8 \%, 39.1 \%)\end{array}$ & $0.0 \%$ & $12.5(8.7,19.0)$ & \multirow[t]{2}{*}{0.5649} \\
\hline No & $\begin{array}{l}21.8 \% \\
(14.5 \%, 29.9 \%)\end{array}$ & $\begin{array}{l}11.9 \% \\
(6.3 \%, 19.2 \%)\end{array}$ & $9.0(8.0,12.9)$ & \\
\hline \multicolumn{5}{|c|}{ Bone Mets Only } \\
\hline Yes & $\begin{array}{l}11.1 \% \\
(2.8 \%, 25.9 \%)\end{array}$ & $\begin{array}{l}3.7 \% \\
(0.3 \%, 15.9 \%)\end{array}$ & $9.0(5.9,9.8)$ & \multirow[t]{2}{*}{0.0681} \\
\hline No & $\begin{array}{l}26.2 \% \\
(19.2 \%, 33.7 \%)\end{array}$ & $\begin{array}{l}8.3 \% \\
(3.0 \%, 17.1 \%)\end{array}$ & $11.9(8.7,14.9)$ & \\
\hline \multicolumn{5}{|c|}{$\begin{array}{l}\text { Bronchioalveolar } \\
\text { Component }\end{array}$} \\
\hline Yes & $\begin{array}{l}55.6 \% \\
(20.4 \%, 80.5 \%)\end{array}$ & $\begin{array}{l}37.0 \% \\
(6.8 \%, 69.3 \%)\end{array}$ & $50.0\left(0.43,{ }^{*}\right)$ & \multirow[t]{2}{*}{0.0106} \\
\hline No & $\begin{array}{l}20.8 \% \\
(14.8 \%, 27.6 \%)\end{array}$ & $\begin{array}{l}4.5 \% \\
(1.2 \%, 11.5 \%)\end{array}$ & $9.7(8.3,12.7)$ & \\
\hline \multicolumn{5}{|c|}{ Nodal Stage } \\
\hline 0 & $\begin{array}{l}40.1 \% \\
(25.9 \%, 53.9 \%)\end{array}$ & $\begin{array}{l}17.0 \% \\
(6.2 \%, 32.4 \%)\end{array}$ & $15.3(9.7,28.5)$ & \multirow[t]{2}{*}{0.0083} \\
\hline $1-3$ & $\begin{array}{l}14.6 \% \\
(8.8 \%, 21.8 \%)\end{array}$ & $\begin{array}{l}7.6 \% \\
(2.9 \%, 15.4 \%)\end{array}$ & $8.8(7.8,11.1)$ & \\
\hline
\end{tabular}

* could not be estimated, based on the pattern of the data

\section{Factors Associated with Improved Survival}

Univariate analysis of several demographic factors including; gender, treatment, smoking history, lung surgery, radiation therapy, chemotherapy, location of metastatic disease, nodal stage and bronchioalveolar histology was performed. Of these, the factors that were associated with a statistically significant survival benefit in our patients were: having undergone lung surgery, female gender, never smokers, bronchialveolar histology, and NOTNM nodal stage. There was no statistically significant association with lung metastases only, brain mets, bone mets only, chemotherapy administration. Interestingly, radiation therapy administration did not seem to improve survival. This data is summarized in Table 2.
Lung Surgery Contributes to Improved Survival in Patients Receiving Erlotinib

Interestingly, the survival analysis of the 174 patients cohort revealed that MAL patients receiving erlotinib had a statistically significant $(P=0.0160)$ inferior LTS compared with the non-erlotinib MAL patients (Figure 1). The results were even more impressive because both the short term 24 months survival and the median survival was better in the erlotinib group: $42.4 \%$ $(25.6 \%, 58.3 \%)$ vs $18.8 \%(12.7 \%, 25.8 \%)$ and, respectively, 18.6 months (12.9-37) vs 8.6 months $(7.6,10.1)$ (Figure 1$)$. 


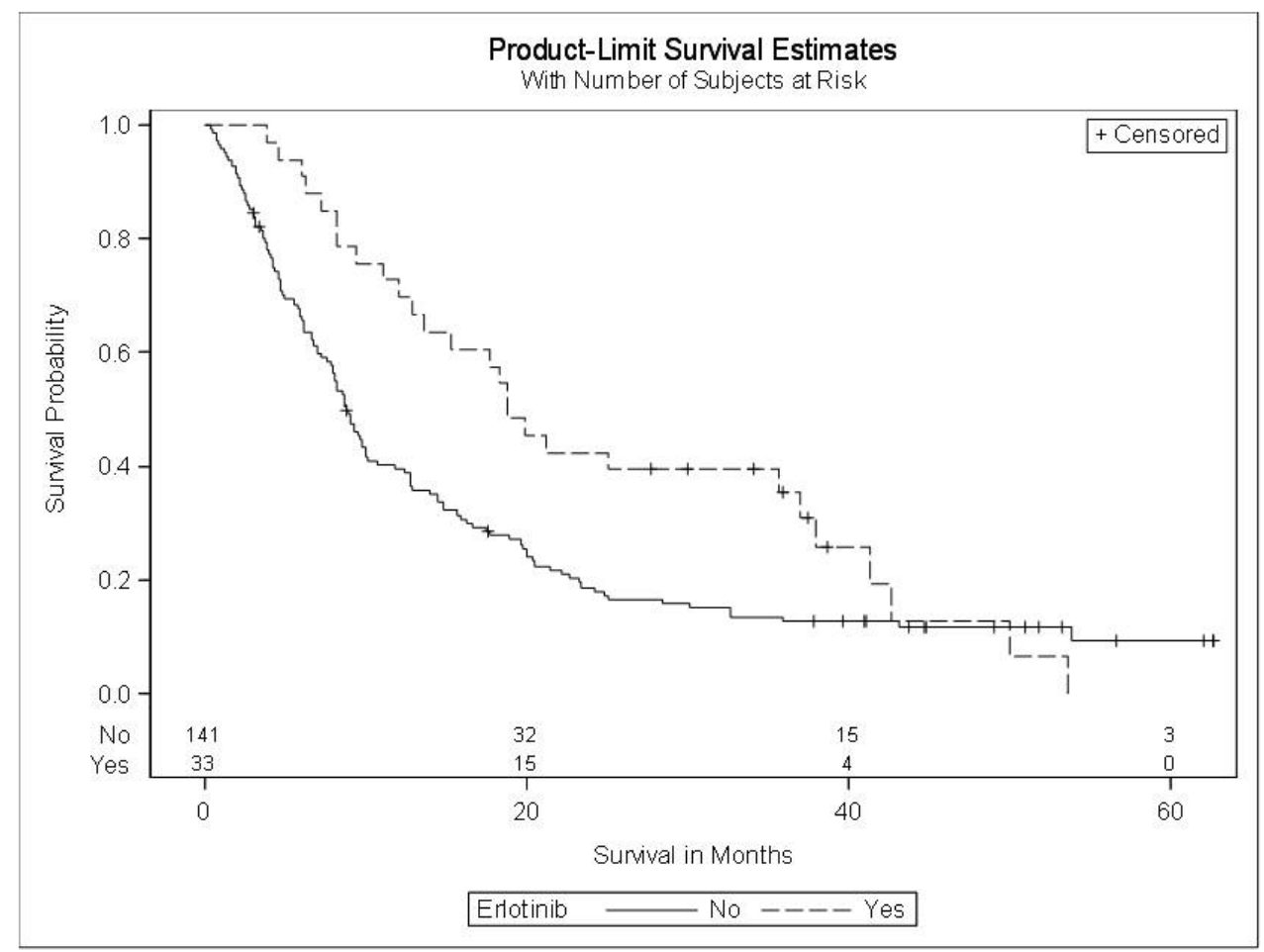

Figure 1: Summarizes the survival of patients on erlotinib therapy versus non-erlotinib therapy. At the 40-month time point, there were 4 patients observed to be alive in the erlotinib group versus 15 in the non-erlotinib group.

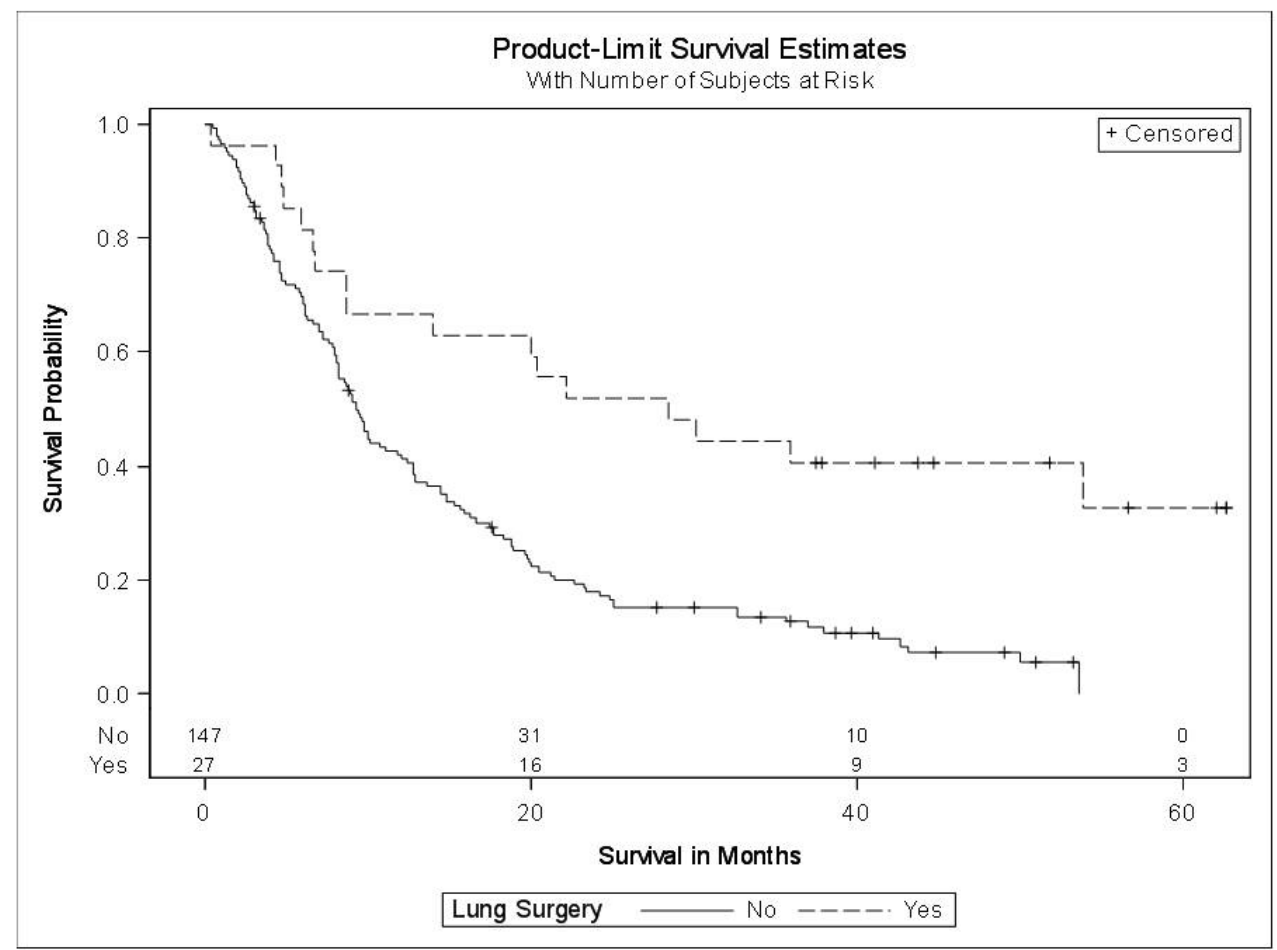

Figure 2: Summarizes the survival of patients with lung surgery versus non-lung surgery 


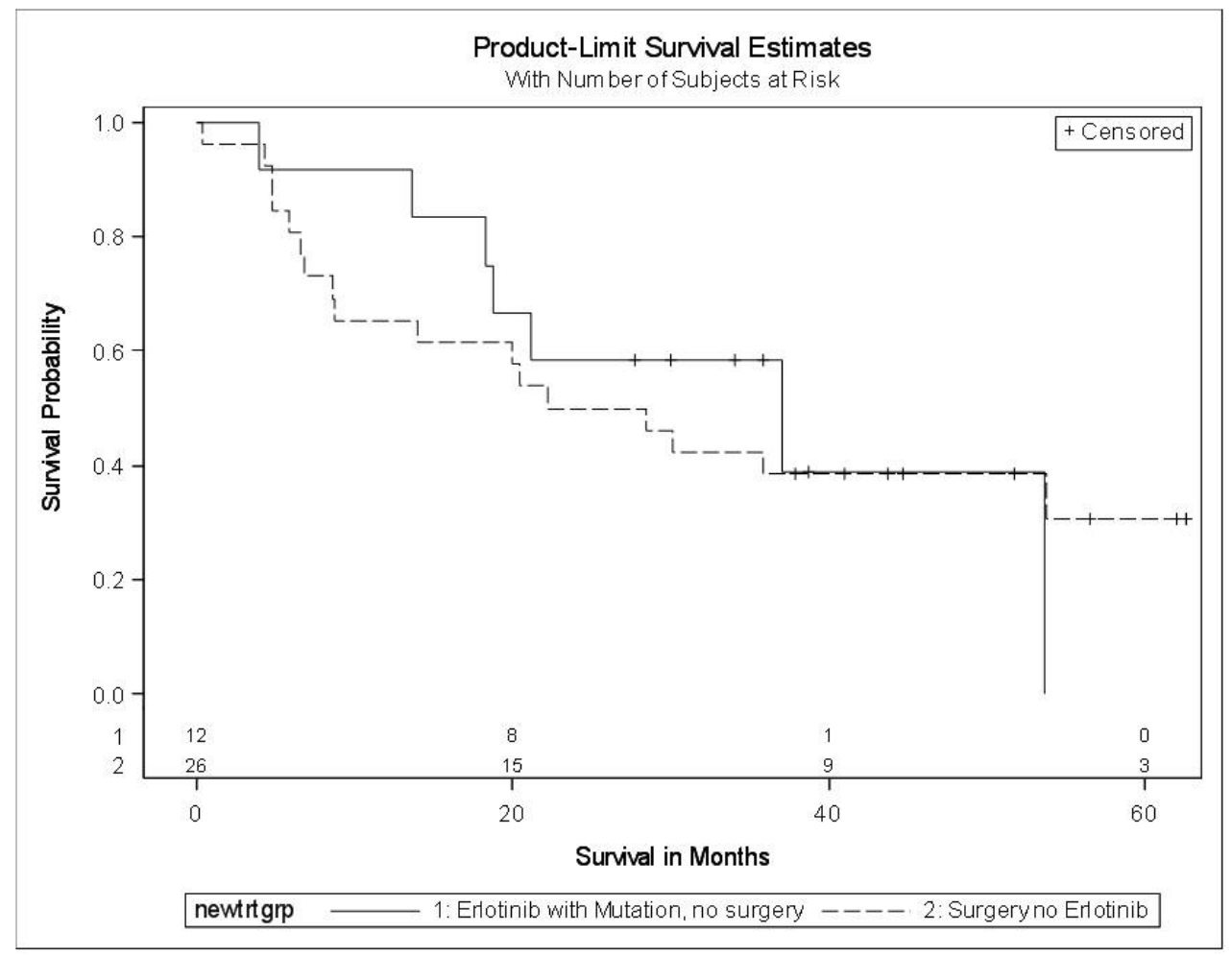

Figure 3: Summarizes the benefit of surgery versus erlotinib in patients with EGFR mutations. Given the improvement in survival with surgery, this figure compares survival benefit of surgery in the non-erlotinib group vs the benefit of erlotinib in the group of patients with tumors harboring EGFR mutations.

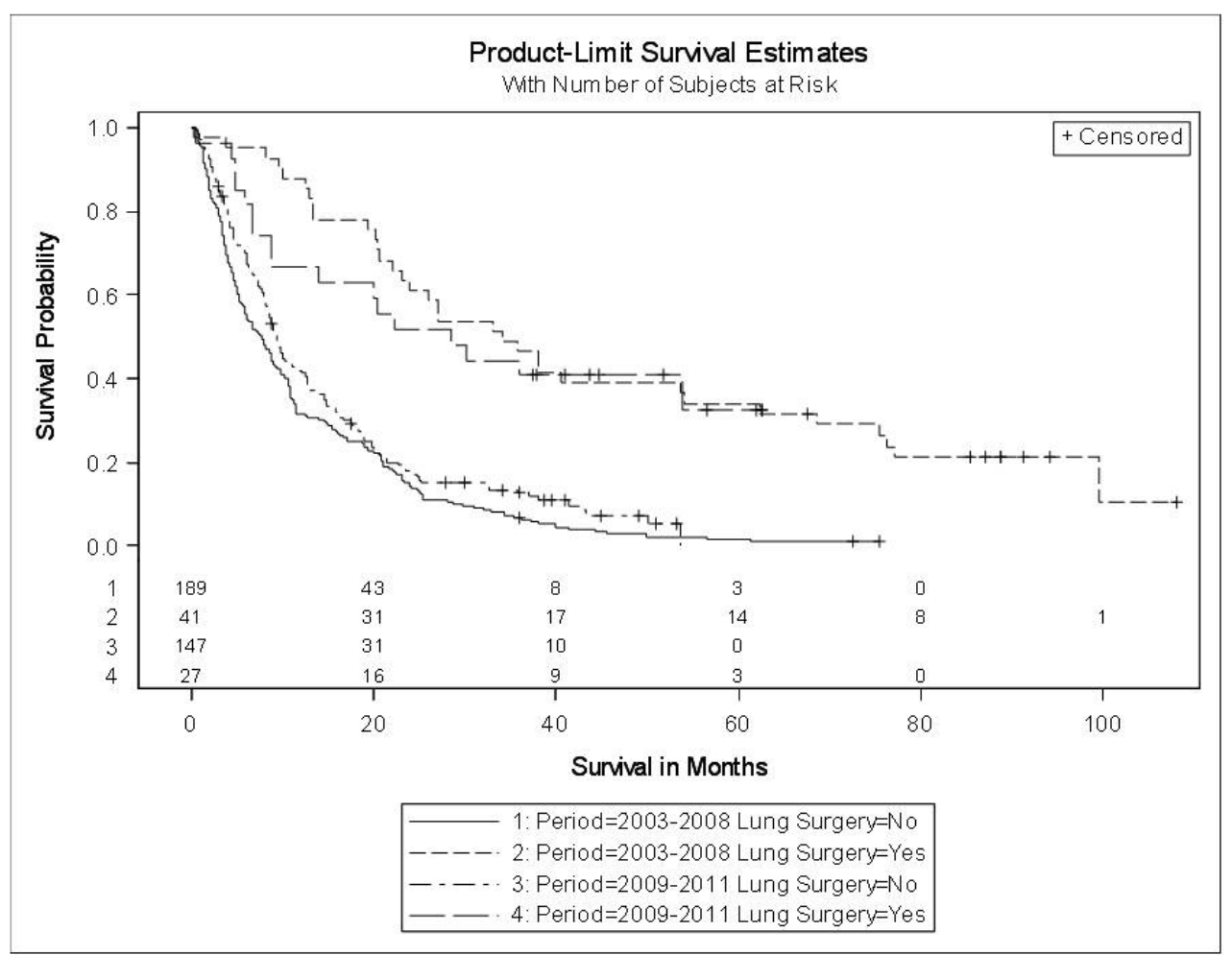

Figure 4: Kaplan Meier survival curves of lung surgery vs non-lung surgery at different time periods (2003-2008) and (2009-2011), respectively. 


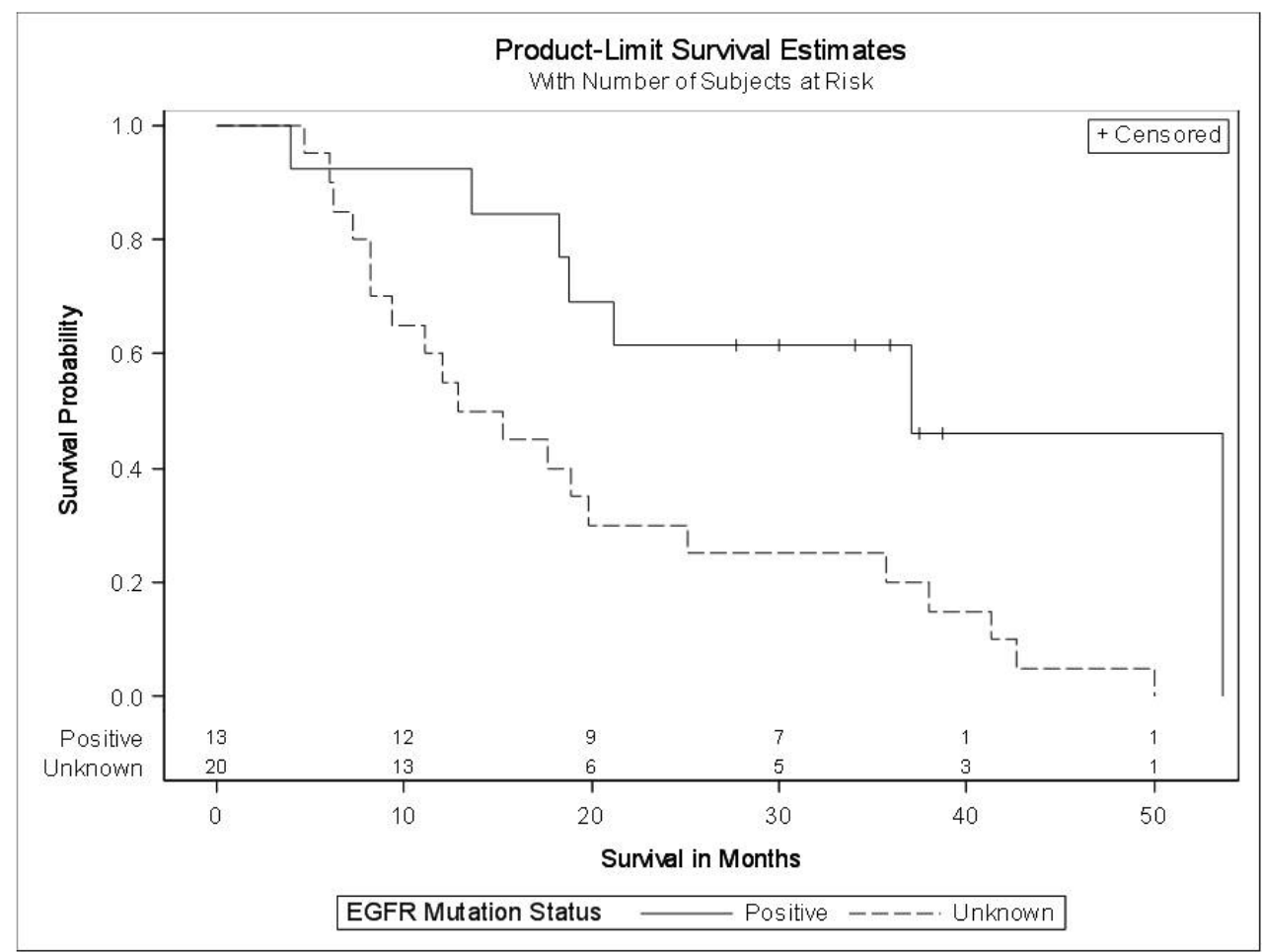

Figure 5: Kaplan Meier survival curves of EGFR mutation status positive (13 patients) vs EGFR mutation status unknown (20 patients)

Given that having had lung surgery was found to have a statistically significant effect on survival, we performed Kaplan Meier analysis of this particular group of patients as well. Patients that had lung surgery had significantly better 24 months, 60 months, and median survival than patients that did not have lung surgery. 24 months benefit was $51.9 \%(31.9 \%$ to $68.5 \%)$ vs $17.9 \%$ (12.1\% to $24.7 \%) .60$ months benefit was $32.6 \%(14.0 \%$ to $52.8 \%)$ vs $0.0 \%$ and median survival benefit was 28.5 months $\left(8.7^{*}\right)$ vs 9.3 months ( 8.1 to 11.9 ). This was strongly statistically significant $(<0.0001)$. (Figure 2.)

Treatment with erlotinib was compared to the treatment with surgery particularly for the patients with EGFR mutations. The 24 months and the median survival favored the erlotinib EGFR mutated tumors group, $58.3 \%(27.0 \%, 80.1 \%)$ vs $50.0 \%(29.9 \%$, $67.2 \%)$ and 37.0 months $(13.6,53.7)$ vs 25.3 (8.7, * could not be estimated), respectively, but the 60 months survival was favoring the non-erlotinib surgery group, $30.8 \%$ (12.8\%,
$50.8 \%)$ vs $0.0 \%$. These results were not statistically significant. ( $p=0.8335)$. (Figure 3 ).

In order to further investigate the survival advantage brought by surgery, we also investigated a cohort of patients diagnosed with MAL between 2003-2008. The results were the same with the 2009-2011 patient cohort, with a net advantage in terms of survival at 24 months, 60 months for the patients that had lung surgery vs the patients that did not have lung surgery. The 24 months benefit was $61.0 \%$ (44.4\%, $74.0 \%)$ vs $14.3 \%(9.8 \%, 19.7 \%)$, the 60 months benefit was $34.1 \%(20.3 \%, 48.5 \%)$ vs $1.7 \%$ $(0.5 \%, 4.5 \%)$ and the median survival benefit was 34 months $(22.0,54.0)$ vs 7.6 months $(5.7,9.1)$ and again this was strongly statistically significant $(<0.0001)$. (Figure 4$)$.

\section{Erlotinib Improves Survival for Pa- tients with EGFR mutations}

It is important to note that the cohort of patients receiving erlotinib included a combination of patients with $(\mathrm{N}=13)$ or without 
documented EGFR mutation ( $\mathrm{N}=20)$. Thus, a comparison of the survival between the patients in the erlotinib group with EGFRmutated tumors vs the patients in the erlotinib group with unknown mutational status of their tumors was performed as well. There was a statistically significant advantage in terms of the 24 months survival for the patients taking erlotinib with EGFR-mutated tumors vs the patients taking erlotinib with an unknown mutational status of their tumors (Figure 5).

\section{Discussion}

In our retrospective cohort study the only treatment modality that significantly improved LTS was lung surgery. This is a striking finding as NCCN guidelines only considers surgery as a treatment option in MAL with isolated lesions (15). Our observations are also supported by the results of a retrospective Chinese study that reported a 5year disease free survival (DFS) rate and an overall survival (OS) rate of $59.6 \%$ and $82.4 \%$, respectively, in patients with multiple adenocarcinomas of the lung located either in the ipsilateral or contralateral lung that were treated with surgery (16). Also, more recently, another Chinese study (24) reported an estimated 3 -year OS of $42.2 \%$ in 88 patients with metastatic lung cancer (77.3\% adenocarcinomas) treated with surgery as part of a multimodality treatment plan. Univariate analysis showed age, sex, smoking history, clinical T stage, tumor histology, and site of metastases, treatment for metastases and adjuvant treatment as the major factors that were significantly associated with $O S$ of patients $(P<0.05)$. No prognostic significance was observed with respect to Charlson Comorbidity Index score, clinical $\mathrm{N}$ stage and extent of pulmonary resection. It is important to note that for our cohort we compared N0 with N1-3 disease as opposed to the Zhang et al. that compared N0-1 with N2-3 disease. After adjusting in multivariate analysis, only age, clinical $\mathrm{T}$ stage, site of metastases and adjuvant treatment remained statistically significant for prognostic prediction.

It is important to note that in our 20092011 cohort the majority, $67 \%$, (18/27), of patients had a lobectomy or a pneumonectomy compared to the 2003-2008 cohort when only $43 \%$ (18/42) of patients had advanced surgery; in 2009-2011 period the majority of patients had a wedge resection with similar survival benefit. In large randomized series, lobectomy showed to have survival benefit over wedge resection, and is considered standard of care now in USA. A note of caution is needed though. Some patients in these retrospective cohorts were staged according to the TNM 6th edition. In TNM $6^{\text {th }}$ edition, patients with lesions of identical histology located in a different lobe of the ipsilateral lung were considered $M 1$, and therefore stage IV, as opposed to the TNM $7^{\text {th }}$ and TNM $8^{\text {th }}$ editions in which these lesions are considered T4 disease, and therefore stage IIIA/IIIB (17). Another limitation of our study is that a retrospective review of pathology and/ or molecular analysis of the resected tumors was not performed, and it is not known whether some of the lung lesions represented multiple primaries versus metastases.

It has been well established that there is a higher incidence of brain metastases in EGFR mutated MAL patients $(70 \%)$ compared to EGFT WT (38\%) (10). The high incidence of brain metastases in MAL patients with EGFR mutated tumors was also confirmed in the 13 EGFR mutated patients in our series. 8/13(62\%) patients with EGFRmutated tumors in the erlotinib group had brain metastases vs $48 / 141$ (34\%) patients in the non-erlotinib group. Other studies have suggested that the biology of the EGFR mutated tumors intrinsically predisposes the patients to wide spread metastases and does not allow them to have potentially curable surgery. In a report from Japan comparing patients with MAL with or without somatic EGFR-mutations, the EGFR mu- 
tated group (98 patients analyzed) had a significantly greater number of metastatic lesions in the brain and bone, as compared to the wild-type group [(148 patients analyzed), brain: median (range) 3(1-93) vs 2 (1-32), $\mathrm{p}=0.023$; bone: 3 (1-12) VS. 2 (1-270; $\mathrm{P}=0.035$, respectively)]. In addition, EGFR mutations were significantly more frequent in patients that had multiple lung lesions compared to those that did not. The authors concluded that EGFR signaling may contribute to multiple metastases within the lung, as well as to the brain and bone (11). Thus, one confounding factor in our cohort is that the patients who ultimately underwent surgery, may have had an overall lower burden of disease, rendering them surgical candidates in the first place and having an impact on their outcomes.

Currently, surgery is not listed among the treatment choices in the metastatic lung cancer treatment guides (NCCN Guidelines, for example, reference 15). However, there have been reports of patients undergoing lung surgery in certain circumstances with improved outcomes. For example, at the opening ceremony of 16th IASCL World Conference on lung cancer that took place in September 2015 in Denver, Colorado, Emily Bennet Taylor, a metastatic lung cancer survivor, brought to the attention of the participants that surgery is an important treatment modality for some patients with metastatic lung cancer that can lead to cure in some of them, like herself. When she was 28 years old, Emily was diagnosed with metastatic lung cancer confined to the lungs and, after having an excellent response to 6 cycles of neo-adjuvant chemotherapy, she had pneumonectomy of her right lung followed by radiotherapy. Four years and a half later, she was still in complete remission and through her commitment and courage, she became an inspiration to the lung cancer patients community all over the world. There have been several retrospective studies that showed improved outcomes using an aggressive surgical management in selected patients with oligometastatic disease defined as patients who present with single organ site of synchronous or metachronous disease with no evidence of lymphatic spread (12).

Another consideration is that when lung cancer is multifocal, it is often difficult to distinguish separate lung primaries from intrapulmonary metastases. An argument favoring lung surgery in these cases is a report describing multiple different genetic mutations in multiple synchronous lung adenocarcinoma- some sensitive other resistantto EGFR targeted TKIs (13).

A large retrospective analysis of 2094 Chinese patients treated with surgery defined as either "radical" or "palliative", examined the difference in outcomes for 363 patients treated post-operatively with TKI and also analyzed based on the type of EGFR mutation. Overall survival in patients with EGFR exon 19 deletion was superior to that of exon $21 \mathrm{~L} 858 \mathrm{R}$ mutations. This suggests that in patients treated with both adjuvant TKIs, there may be a difference in survival based not only on the presence of an EGFR mutation, but also on the exact type of mutation (14).

The results of our retrospective study did not provide a definitive answer to the question whether erlotinib increases LTS in patients with EGFR-mutated MAL. Recently the results of a large retrospective Chinese study suggested that an age younger than 60 , absence of extrathoracic spread and EGFR TKI treatment duration of more than one year may play an important role in survival beyond five years (18).

The study of five-year survival in patients with EGFR treated with TKI by Lin et al. unfortunately did not comment on how many patients underwent surgical treatment. However, they did find that patients with no extrathoracic metastases had improved outcomes. It is unclear if this group did also have surgical interventions as part of their treatment, which may have contributed to the prolonged survival. In addition, their co- 
hort was treated between 2002-2009, when TKI use and surgical approaches were somewhat different compared to after 2009, as previously mentioned.

It is conceivable that their results are more similar to what was shown by us in our 2003-2008 historical cohort (7). The main difference between our study and the study of Lin et al is the fact that we looked beyond the EGFR positivity and erlotinib use to other factors (i.e. surgery) that may impact long term metastatic lung cancer survival.

Lastly, an important limitation of our study was that the erlotinib group included both patients with and without EGFR mutation. Due to the limited number of proven EGFR mutated patients in our retrospective cohort, we are unable to determine whether or not the combination of surgery plus TKI vs. surgery alone had an impact in this group.

\section{Conclusions}

The factors associated with long-term survival in our retrospective cohort of 174 patients diagnosed with MAL between 20092011 were: female gender $(p=0.0019)$, lung surgery $(p<0.0001)$, early nodal stage (N0 disease $)(p<0.0083)$ and bronchioalveolar histology $(p=0.0106)$. The presence of metastatic disease localized only to the lungs was of borderline statistical significance $(p=0.0054)$. In our patients with MAL the only treatment modality that improved LTS in a statistically significant way was lung surgery.

In 2021 the drug of choice for the front line treatment of EGFR mutated MAL became osimertinib and erlotinib is no longer used in this setting. As reported recently by Ramalingam et al. in NEJM (19) the 3 years survival in patients treated with osimertinib is $54 \%$ and it is projected that the 5 -year survival of these patients is approximately $30 \%$ (20). The benefit of adding TKI post surgery in the adjuvant setting of localized lung cancer has been already established $(21,22)$. Also, recently as shown by a Chinese group, surgical treatment may improve survival in patients with EGFR mutated MAL treated with EGFR inhibitors that responded to the treatment (23).

As shown by another group recently (24), our retrospective study also demonstrated that it is possible to identify certain subcategories of patients with MAL that can benefit of surgery in the setting of a multimodality cancer treatment. In the future, it will be interesting to investigate in a prospective setting whether the addition of local treatment modalities (i.e. surgery or stereotactic radiotherapy) may further improve the survival of selected patients with EGFR mutated MAL treated with osimertinib.

Author's contribution: Doru Paul contributed to the design of the study, the data analysis and the writing of the article. Marissa Rybstein contributed to the writing of the article.

Statements: None.

Consent for publication: Study included retrospective data and the patients 'information was de-identified.

Ethics approval: Study approved by the Northwell IRB.

Previous publication: We declare that this paper was not published nor was submitted to be reviewed for publication in another journal.

Conflict of Interests: Authors report no conflict of interest.

Funding Sources: This research did not receive any specific grant from funding agencies in the public, commercial, or not-for-profit sector. 


\section{References}

1. Lung and Bronchus Cancer - Cancer Stat Facts [Internet]. [cited 2019 Feb 10]. Available from: https://seer.cancer.gov/statfacts/html/lungb.html

2. Bethune G, Bethune D, Ridgway N, Xu Z. Epidermal growth factor receptor (EGFR) in lung cancer: an overview and update. J Thorac Dis. 2010 Mar;2(1):48-51.

3. Da Cunha Santos G, Shepherd FA, Tsao MS. EGFR mutations and lung cancer. Annu Rev Pathol. 2011;6:4969.

4. Shepherd FA, Rodrigues Pereira J, Ciuleanu T, Tan EH, Hirsh V, Thongprasert S, et al. Erlotinib in previously treated non-small-cell lung cancer. N Engl J Med. 2005 Jul 14;353(2):123-132.

5. Rosell R, Carcereny E, Gervais R, Vergnenegre A, Massuti B, Felip E, et al. Erlotinib versus standard chemotherapy as first-line treatment for European patients with advanced EGFR mutation-positive non-small-cell lung cancer (EURTAC): a multicentre, open-label, randomised phase 3 trial. Lancet Oncol. 2012 Mar;13(3):239-246.

6. Zhou C, Wu Y-L, Chen G, Feng J, Liu X-Q, Wang C, et al. Erlotinib versus chemotherapy as first-line treatment for patients with advanced EGFR mutation-positive non-small-cell lung cancer (OPTIMAL, CTONG-0802): a multicentre, open-label, randomised, phase 3 study. Lancet Oncol. 2011 Aug;12(8):735-742.

7. Lee CK, Davies L, Wu Y-L, Mitsudomi T, Inoue A, Rosell R, et al. Gefitinib or Erlotinib vs Chemotherapy for EGFR Mutation-Positive Lung Cancer: Individual Patient Data Meta-Analysis of Overall Survival. J Natl Cancer Inst. 2017 Jun 1;109(6).

8. Lin JJ, Cardarella S, Lydon CA, Dahlberg SE, Jackman DM, Jänne PA, et al. Five-Year Survival in EGFRMutant Metastatic Lung Adenocarcinoma Treated with EGFR-TKIs. J Thorac Oncol. 2016 Apr;11(4):556-565.

9. Mok TS, Wu Y-L, Thongprasert S, Yang C-H, Chu D-T, Saijo N, et al. Gefitinib or carboplatin-paclitaxel in pulmonary adenocarcinoma. N Engl J Med. 2009 Sep 3;361(10):947-957.

10. Fujimoto, D, Ueda, H, Shimizu, R, Kato, R, Otoshi, T, Kawamura, T et al. Features and prognostic impact of distant metastasis in patients with stage IV lung adenocarcinoma harboring EGFR mutations: the importance of bone metastasis. Clinical experimental metastasis 2014; 31: 543-551.

11. Kelly WJ, Shah NJ, Subramaniam DS. Management of Brain Metastases in Epidermal Growth Factor Receptor Mutant Non-Small-Cell Lung Cancer. Front Oncol. 2018 Jul 3;8:208.

12. Rafael, OC, Lazzaro, R and Hasanovic, A. Molecular Testing in Multiple Synchronous Lung Adenocarcinomas: Case Report and Literature Review. International Journal of Surgical Pathology. Published on line on Sep 8, 2015.

13. Patrini D, Panagiotopoulos N, Bedetti B, Mitsos S, Crisci R, Solli P, et al. Surgical approach in oligometastatic non-small cell lung cancer. Ann Transl Med. 2018 Mar;6(5):93.

14. Yang W, Gao Y, Li X, Zhang J, Liu T, Feng X, et al. Postoperative survival of EGFR-TKI-targeted therapy in non-small cell lung cancer patients with EGFR 19 or 21 mutations: a retrospective study. World J Surg Oncol. 2017 Nov 6;15(1):197.

15. NCCN Clinical Practice Guidelines in Oncology [Internet]. [cited 2021Nov 10]. Available from: https://www.nccn.org/professionals/physician_gls/pdf/nscl.pdf

16. Zhang Z, Gao S, Mao Y, et al. Surgical Outcomes of Synchronous Multiple Primary Non-Small Cell Lung Cancers. Sci Rep 2016; 6:23252.

17. UyBico SJ, Wu CC, Suh RD, Le NH, Brown K, Krishnam MS. Lung cancer staging essentials: the new TNM staging system and potential imaging pitfalls. Radiographics. 2010 Sep;30(5):1163-81. 
18. Huang CY, Chen BH, Chou WC, Yang CT, Chang JW. Factors associated with the prognosis and long-term survival of patients with metastatic lung adenocarcinoma: a retrospective analysis. J Thorac Dis. 2018 Apr;10(4):20702078. Erratum in: J Thorac Dis. 2018 Jul;10(7):E604.

19. Ramalingam SS, Vansteenkiste J, Planchard D, et al. FLAURA Investigators. Overall Survival with Osimertinib in Untreated, EGFR-Mutated Advanced NSCLC. N Engl J Med. 2020. 382(1):41-50

20. Dyer M, Gree, M, Jones, S et al. Estimating long-term survival of previously untreated patients with EGFR mutation-positive (EGFRm) advanced non-small cell lung cancer (NSCLC) who received osimertinib in the FLAURA study. 2019. Journal of Clinical Oncology 37, no. 15_suppl e20560.

21. Huang Q, Li J, Sun Y, et al. Efficacy of EGFR tyrosine kinase inhibitors in the adjuvant treatment for operable non-small cell lung cancer by a meta-analysis. Chest 2016;149:1384-1392.

22. Wu, Y-L, Tusboi, M, He, J et al. Osimertinib in Resected EGFR-Mutated Non-Small-Cell Lung Cancer. N Engl J Med. 2020. 383:1711-1723.

23. Chien YN, Lin YC, Chang CL, Lin WC, Wu SY. Thoracic surgery improved overall survivalin patients with stage IIIB-IV epidermal growth factor receptor-mutant lungadenocarcinoma who received and responded to tyrosine kinase inhibitor treatment. Lung Cancer (Amsterdam, Netherlands). 2021;162:29-35.

24. Zhang C, Wang L, Li W, Huang Z, Liu W, Bao P, Lai Y, Han Y, Li X, Zhao J. Surgical outcomes of stage IV non-small cell lung cancer: a single-center experience. J Thorac Dis. 2019;11(12):5463-5473 